\title{
Studies on relative catalytic efficiencies of zinc and aluminium on nucleation of dispersed bismuth droplets
}

\author{
SANJAY CHAUBEY \\ Department of Physics, Motilal Nehru National Institute of Technology, Allahabad 211 004, India
}

MS received 27 October 2006; revised 21 February 2007

\begin{abstract}
In $\mathrm{Zn}-\mathrm{Bi}$ and $\mathrm{Al}-\mathrm{Bi}$ systems, both of which belong to monotectic class, dispersion of second phase particles within the matrix have been produced through rapid solidification processing (RSP) route. In order to understand relative catalytic efficiencies of $\mathrm{Zn}$ and $\mathrm{Al}$ matrices in catalyzing nucleation of $\mathrm{Bi}$ particles entrapped in the respective metal matrices, thermal analysis in constant program mode was performed. Thermal analyses revealed that $\mathrm{Bi}$ undercools by $132^{\circ}$ in $\mathrm{Zn}$ matrix and by $157^{\circ}$ in $\mathrm{Al}$ matrix. Thermodynamic barrier to nucleation $\left(\Delta G^{*}\right)$ for $\mathrm{Bi}$ has also been calculated, which is $39.8 \mathrm{kcal} / \mathrm{mole}$ and $47.085 \mathrm{kcal} / \mathrm{mole}$, in $\mathrm{Zn}$ and $\mathrm{Al}$ matrices, respectively at the maximum recorded undercoolings.
\end{abstract}

Keywords. Monotectic; nucleation; undercooling; bismuth.

\section{Introduction}

The phenomenon of undercooling exhibited by liquid metals and alloys below their thermodynamic freezing temperature has been given due importance in the field of materials research because of its invaluable use in understanding the fundamentals of nucleation behaviour (Turnbull 1952, 1969). Of the two, viz. homogeneous and heterogeneous nucleation, the former is considered as an unlikely event while the latter is more physically probable and mostly encountered in practical situations. The degree of undercooling is of immense importance in determining many microstructural developments in the solid state and thus it has a marked influence on the properties of the final product (Perepezko et al 1979; Perepezko 1980, 1984; Mueller et al 1985; Graves and Perepezko 1986; Devaud and Turnbull 1987; Ojha 2001; Aoyama et al 2004; Fecht and Johnson 2004). Several experimental techniques for extending the range of observable undercooling are available (Turnbull 1950a; Turnbull and Cech 1950; Wang and Smith 1950; Duwez et al 1960; Fehling and Scheil 1962; Shiraishi and Wood 1964; Rasmussen and Loper Jr. 1975; Southin and Chadwick 1978; Lacy et al 1981). One of the most attractive and powerful methods amongst them for extending the undercooling limit is the droplet technique (Vonnegut 1948), because of its efficient isolation capability, which was later on employed successfully by Turnbull $(1950 \mathrm{~b}, 1952)$ and his coworkers (Turnbull and Cech 1950). Droplet configuration has also been frequently observed in monotectic systems (Dobatkin et al 1979). When such an alloy melt is subjected to

(chaubey55@yahoo.com) ultra rapid cooling, the process restricts layering phenomena, which is common in liquid monotectic alloys, leading to granulation of the second phase particles (Chattopadhyay and Ramachandrarao 1980; Chaubey et al 1987, 1988). As solidification process of liquid droplets is profoundly influenced by the surrounding matrix (Chattopadhyay 1992), Zn-Bi and Al-Bi systems have been presently chosen to study the nucleation behaviour of entrapped Bi particles in respective metal matrices and also to assess the catalytic power of substrate materials.

\section{Experimental}

Alloys of monotectic and hypermonotectic (equivalent to 20 volume \% $\mathrm{Bi}$ ) compositions of $\mathrm{Zn}-\mathrm{Bi}$ and $\mathrm{Al}-\mathrm{Bi}$ systems were made from high purity metals, by melting the accurately weighed components together in a graphite crucible under an argon atmosphere. The alloy melt was vigorously shaken and then it was allowed to solidify in the crucible under an argon gas cover.

In order to get dispersion of $\mathrm{Bi}$ in the respective metal matrices, gun technique of rapid solidification was employed.

Differential scanning calorimetric analyses were performed using Perkin Elmer DSC II in the constant program mode in order to study the nucleation behaviour of $\mathrm{Bi}$ in the two matrices. Argon gas had been used for purging throughout the experiment.

\section{Results}

Earlier results of Chaubey et al (1987) on rapidly solidified $\mathrm{Zn}-\mathrm{Bi}$ system revealed that size of most of the $\mathrm{Bi}$ 
droplets was $\approx 6 \mathrm{~nm}$ and the value of undercooling, $\Delta T$, for $\mathrm{Bi}$ in $\mathrm{Zn}$ matrix was $132^{\circ}$. Nucleation rate measurements yielded the activation energy barrier to nucleation as $39.8 \mathrm{kcal} / \mathrm{mole}$ at maximum undercooling.

Rapidly solidified Al-Bi products were found to be highly unstable. Within 5 min of quenching, thin foils of the product disintegrated into fine brownish powder. Thicker portions, however, remained stable for nearly $1 \mathrm{~h}$.

Constant heating and cooling thermograms for monotectic (Al-0.45 at.\% $\mathrm{Bi}$ ) and hypermonotectic (Al-10.48 at. $\% \mathrm{Bi}$ ), equivalent to 20 volume $\% \mathrm{Bi}$, compositions of $\mathrm{Al}-\mathrm{Bi}$ system in the rapidly solidified as well as as-cast condition are shown in figures 1-4. Figures 1 and 2 are the differential scanning calorimetric (DSC) traces for the rapidly solidified $\mathrm{Al}-\mathrm{Bi}$ system. In the DSC runs, thick portions of the foil, which do not disintegrate for atleast $1 \mathrm{~h}$, were used. Figures 3 and 4 represent thermograms for the as-cast Al-Bi system.

Melting temperature, $T_{\mathrm{m}}(\approx 540 \mathrm{~K})$, recorded in the thermograms of figures 1 and 2 represents melting of fine $\mathrm{Bi}$ particles entrapped in the $\mathrm{Al}$ matrix as a result of rapid solidification. Apart from this a very small endothermic transition is also seen at $\approx 440 \mathrm{~K}$. Successive heating and cooling of the samples did not affect the shape and hence area under the peak appearing at $\approx 440 \mathrm{~K}$. Cooling thermogram of figure 1 shows only one crystallization exotherm appearing at $386 \mathrm{~K}$ whereas the thermogram of figure 2 indicates the occurrence of two exothermic events at $446 \mathrm{~K}$ and $386 \mathrm{~K}$, respectively. The maximum undercooling, $\Delta T$ (difference of melting temperature and the temperature at which last exothermic event occurred), attained by $\mathrm{Bi}$ particles, is thus $154^{\circ}$, equivalent to

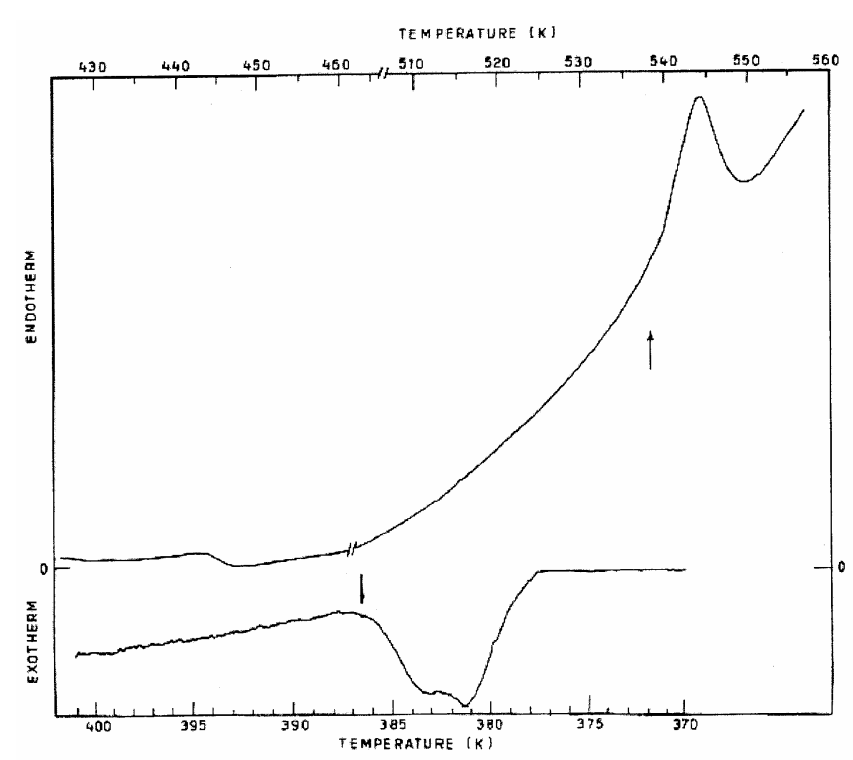

Figure 1. DSC thermogram recorded at heating and cooling rates of $2.5 \mathrm{~K} / \mathrm{min}$ for rapidly solidified $\mathrm{Al}-0.45$ at.\% $\mathrm{Bi}$. The transformation temperatures are marked by an arrow.
$0 \cdot 285 T_{\mathrm{m}}$, in the $\mathrm{Al}$ matrix. Melting transition observed at $544 \mathrm{~K}$ in the thermograms of figures 3 and 4, for the ascast $\mathrm{Al}-\mathrm{Bi}$ samples, corresponds to melting of pure $\mathrm{Bi}$. There is minute trace of an endothermic event at $\approx 440 \mathrm{~K}$ in figure 4 , which corresponds to hypermonotectic Al-Bi sample, however, there is no indication of any such transition in figure 3 , which corresponds to as-cast $\mathrm{Al}-\mathrm{Bi}$ monotectic samples. During cooling, several of the as-cast Al-Bi monotectic samples showed intermediate exothermic events at different temperatures but the last one appeared at $433 \mathrm{~K}$ in all the samples. Thus the maximum undercooling recorded for $\mathrm{Bi}$ in the as-cast condition of the monotectic compositioned alloy is $\approx 111^{\circ}$ as shown in figure 3 . In case of hypermonotectic $\mathrm{Al}-\mathrm{Bi}$ as-cast samples, the last exothermic peak during cooling was found to appear at $\approx 387 \mathrm{~K}$, i.e. at an undercooling of $\approx 157^{\circ}$ (equivalent to $0.288 T_{\mathrm{m}}$ ) in all the samples as shown in figure 4 . The maximum value of $\Delta T$ for $\mathrm{Bi}$ in as-cast condition of the hypermonotectic alloy is thus almost of the same order of magnitude as for its rapidly solidified counterpart. With the help of cooling thermograms, recorded at a rate of $2.5 \mathrm{~K} / \mathrm{min}$, temperature dependence of nucleation rate for $\mathrm{Bi}$ particles entrapped in Al matrix has been determined at the maximum undercooling and is shown in figure 5 . The thermodynamic barrier to nucleation $\left(\Delta G^{*}\right)$, for Bi has been calculated as $47.085 \mathrm{kcal} / \mathrm{mole}$ in Al matrix from figure 5 by using the expression of Lele et al (1985) for Gibbs free energy change $\left(\Delta G_{\mathrm{v}}\right)$ in the undercooled temperature regime.

\section{Discussion}

It is interesting to note that disintegration of the rapidly solidified product is restricted only to $\mathrm{Al}-\mathrm{Bi}$ system and not for the $\mathrm{Zn}-\mathrm{Bi}$ system (Chaubey et al 1987). As-cast Al-Bi alloys, however, did not show any such tendency for decomposition. In fact, with increase in cooling rates more quenching strains are developed in the final product and these possibly change the surface free energy in a way by which surface becomes highly reactive to oxygen. When such a thin surface is exposed to atmosphere, oxidation is very pronounced and leads to crumbling of the foil immediately. The tendency of disintegration decreases with increase in thickness of the rapidly solidified foils of $\mathrm{Al}-\mathrm{Bi}$ system due to lower cooling rates and hence they are less prone to oxidation at ambient conditions. In fact, cooling rate decreases by two orders of magnitude for an order of increase in the thickness of the foil. Thus, it may be derived that the rapidity of oxidation is inversely proportional to thickness of the foil.

Though direct observation of droplet structure has not been possible for the rapidly solidified foils of $\mathrm{Al}-\mathrm{Bi}$ system owing to its unstable nature, it is believed that $\mathrm{Bi}$ exists as droplets in the Al matrix because of granulation occurring through rapid quenching (Chattopadhyay 


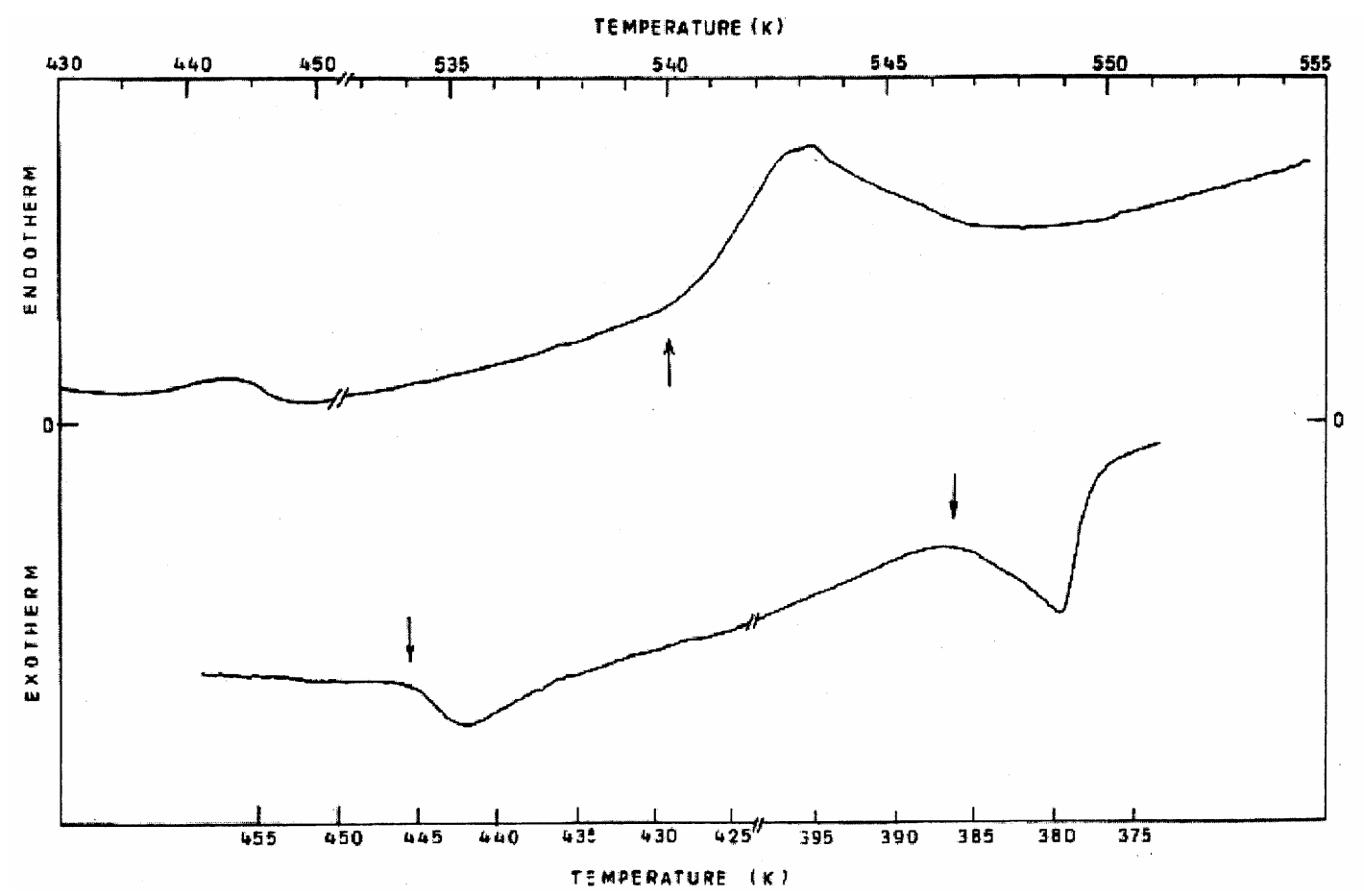

Figure 2. DSC thermogram recorded at heating and cooling rates of $2.5 \mathrm{~K} / \mathrm{min}$ for rapidly solidified $\mathrm{Al}-10.48$ at.\% $\mathrm{Bi}$. The transformation temperatures are marked by an arrow.

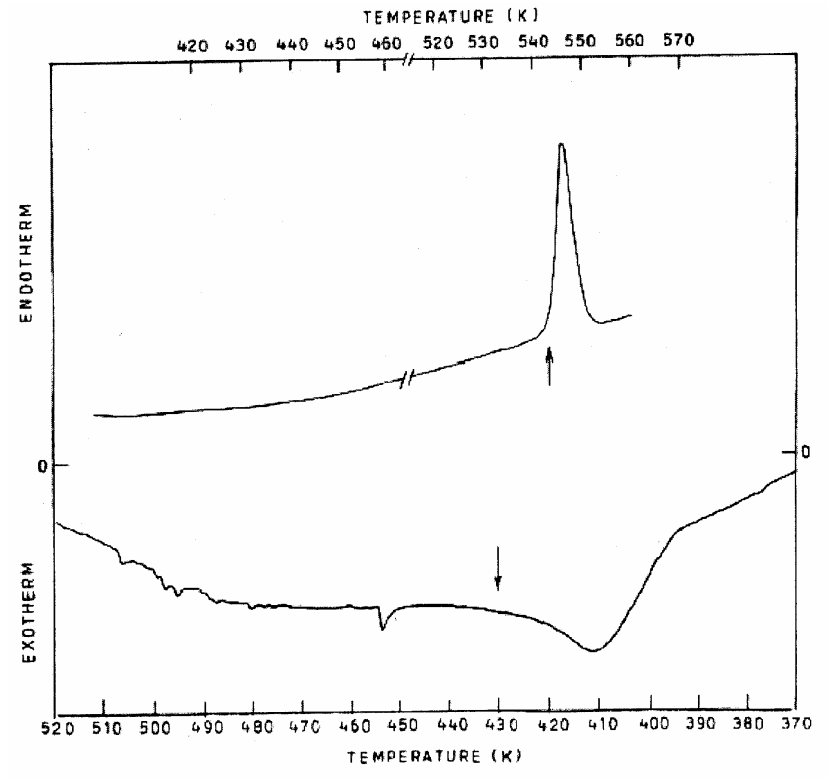

Figure 3. DSC thermogram for the as-cast $\mathrm{Al}-0.45$ at.\% $\mathrm{Bi}$ recorded at heating and cooling rates of $2.5 \mathrm{~K} / \mathrm{min}$. The transformation temperatures are marked by an arrow.

and Ramachandrarao 1980; Chaubey et al 1987, 1988).

The onset of melting at $540 \mathrm{~K}$ (figures 1 and 2) for dispersed $\mathrm{Bi}$ particles obtained through rapid quenching is slightly lower than the melting point of pure $\mathrm{Bi}$ in the as-cast alloys of Al-Bi system (figures 3 and 4). The first experimental observation of depression of melting temperature of small particles $(<50 \mathrm{~nm})$ was demonstrated by Takagi (1954). Coombes (1972) had shown a substantial decrease of the melting temperature of $\mathrm{Pb}$ particles with a radius of $3 \mathrm{~nm}$. Goswami and Chattopadhyay (1996, 1999) have observed an unusual trend in the solidification behaviour of Bi. They showed lowering of melting temperature of $\mathrm{Bi}$ particles embedded in an amorphous $\mathrm{Al}-\mathrm{Fe}-\mathrm{Si}$ alloy, which was explained by formation of domain structures in the particles. The formation of domain structures was attributed to the crystallographic constraint of the spherical shape due to amorphous nature of the matrix. Such a depression in melting temperature of $\mathrm{Pb}$ and $\mathrm{Bi}$ particles in quasicrystalline matrix was explained by Singh and Tsai (2003) in terms of the difference of interface energies between liquid particle and matrix and solid particle and matrix. Bi inclusions in $\mathrm{Al}$ matrix were observed to melt at temperatures at or below the Bi bulk melting point by Thoft et al (1995) also. Average inclusion size ranged from a few $\mathrm{nm}$ to some tens of $\mathrm{nm}$. Bi is known to be the only metallic particle which shows a lowering in melting temperature in the Al matrix (Andersen and Johnson 1995). A notable feature observed in the heating thermograms of figures 1,2 and 4 is the appearance of one more endothermic transition at $\approx 440 \mathrm{~K}$. This temperature did not correspond to the melting points of oxides of $\mathrm{Bi}$ (Weast 1977) and so the presence of any oxide of $\mathrm{Bi}$ was ruled out. Inspection of areas under two 


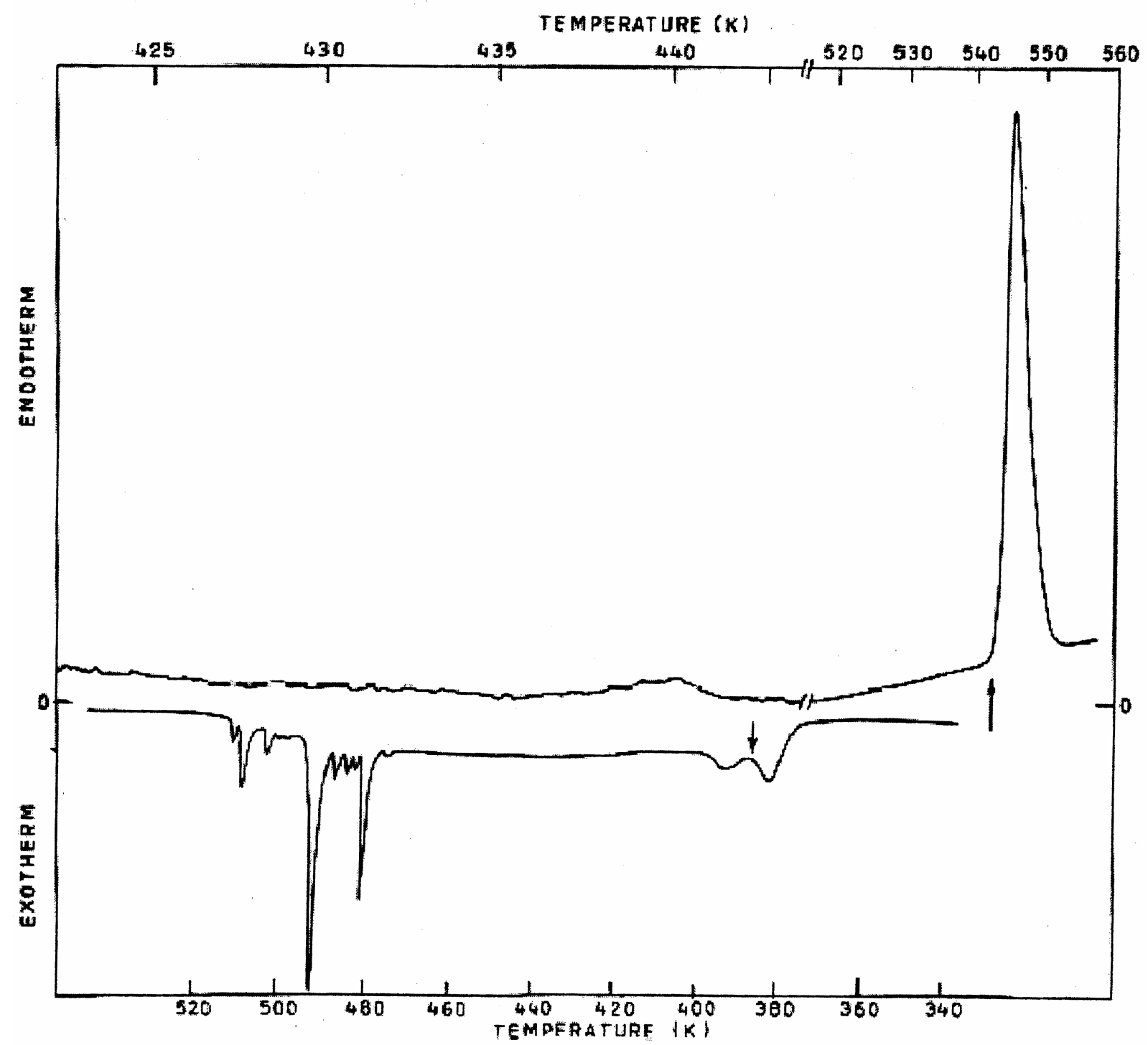

Figure 4. DSC thermogram for the as-cast $\mathrm{Al}-10.48$ at. $\%$ Bi recorded at heating and cooling rates of $2.5 \mathrm{~K} / \mathrm{min}$. The transformation temperatures are marked by an arrow.

melting transitions indicates that volume fraction of the phase appearing at $\approx 440 \mathrm{~K}$ is $<5 \%$ of the total. X-ray diffraction studies did not give clear evidence for the presence of any polymorph of $\mathrm{Bi}$, although $\mathrm{Bi}$ is reported to undergo several polymorphic transformations (Klement et al 1963). However, it may not be possible to detect any polymorph by X-ray diffraction since the volume fraction of the phase is too small. It has already been suggested by Perepezko (1980) that at high undercooling, solidification is initiated by the nucleation of $\mathrm{Bi}$ with different crystal structures. For the additional endotherm observed at approximately same temperature as in the present communication, Perepezko (1980) argued that the structural modification may be the metastable Bi (II) phase. The degree of undercooling obtained by him was of course much higher and this could be the reason for higher volume fraction of $\mathrm{Bi}$ (II) phase observed by him. It is evident from the experiments that crystallization of $\mathrm{Bi}$, entrapped in either $\mathrm{Zn}$ or Al matrix, occurs through several nucleation events. Number of exothermic peaks, at different temperatures, indicates the presence of different types of heterogeneities, each becoming effective at different levels of undercooling.

It is worth noting that with regard to the degree of undercooling, $\Delta T$, there is a close resemblance between the observations on slowly cooled samples of the as-cast and rapidly solidified $\mathrm{Al}-\mathrm{Bi}$ as well as as-cast and rapidly solidified $\mathrm{Zn}-\mathrm{Bi}$ (Chaubey et al 1987) alloys. The maximum level to which Bi undercools in $\mathrm{Al}$ matrix, whether in the droplet configuration obtained through rapid quenching or in the as-cast condition (except for the as-cast samples of $\mathrm{Al}-0.45$ at. $\% \mathrm{Bi}$ ), is $\approx 0 \cdot 28 T_{\mathrm{m}}$. This limit is reduced to 
$0 \cdot 25 T_{\mathrm{m}}$ in the case of Bi-rich droplets in the $\mathrm{Zn}$ matrix (Chaubey et al 1987). An undercooling of $65^{\circ}$ for $\mathrm{Bi}$ in $\mathrm{Zn}$ matrix had been reported by Sundquist and Mondolfo (1961). Turnbull and Cech (1950) reported the value of $\Delta T$ for $\mathrm{Bi}$ as $90^{\circ}$, whereas the value reported by Perepezko (1984) was $227^{\circ}$. Substantial undercooling of $\mathrm{Bi}$ in rapidly solidified products of both the systems have been attributed to effective isolation of nucleation catalysts. Out of the total droplet population, a fraction remains free from nucleation catalysts owing to granulation. Such impurity free Bi particles, apart from the lumps of Bi resulting due to layering and segregation, which is very common and frequently observed in monotectic alloys, also form by a monotectic reaction in the as-cast samples (Dobatkin et al 1979). Hence, these droplets attain the same level of undercooling even in the as-cast condition. Especially in the $\mathrm{Al}-0.45$ at.\% $\mathrm{Bi}$ as-cast monotectic samples it seems layering effect was more pronounced and even if some droplets had formed as a result of monotectic reaction, they were not completely impurity free. This is the cause of lesser undercooling in those samples (figure 3 ). Undercooling results recorded in the present communication is understood in terms of surface catalytic effect. It implies that the matrix, whether $\mathrm{Zn}$ or $\mathrm{Al}$, containing Bi dispersion, provides a suitable surface

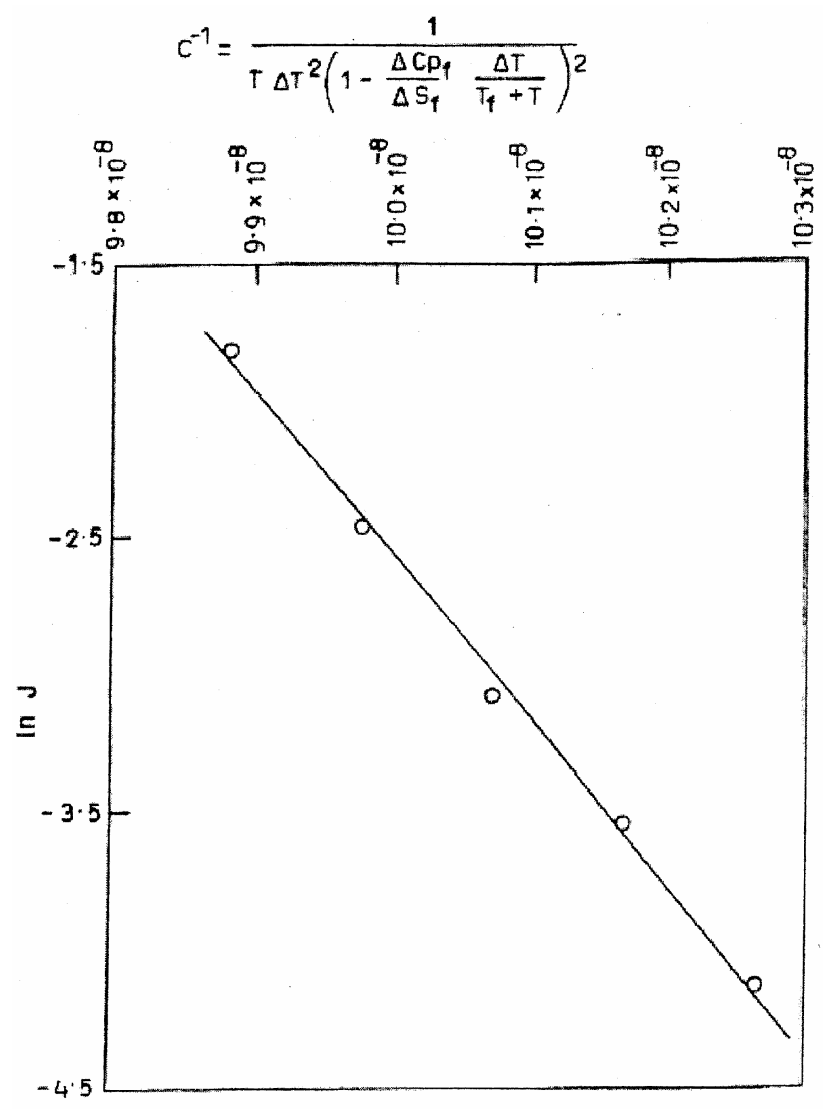

Figure 5. Temperature dependence of the nucleation rate for $\mathrm{Bi}$ in $\mathrm{Al}$. for catalyzing the nucleation of $\mathrm{Bi}$ droplets which are supposed to be relatively free from heterogeneities. Thus the mechanism of heterogeneous nucleation, based on interfacial energy barrier to nucleation becomes operative (Volmer 1929; Fisher 1948; Turnbull 1950a). Accordingly the large undercooling for $\mathrm{Bi}$ is attributed to large $\sigma_{\mathrm{SL}}$ (solid liquid interfacial tension) value for $\mathrm{Bi}$ (Mondolfo et al 1984-85). The nucleation events occurring at lesser undercoolings are also heterogeneous in nature but impurity aided. Majority of $\mathrm{Bi}$ particles exhibiting large undercooling are definitely clean because they are only in contact with solid matrix surface. It would be appropriate to call the responsible nucleation process as clean and contamination free heterogeneous nucleation (Southin and Chadwick 1978). Using droplet technique, Southin and Chadwick (1978) were able to undercool Bi in $\mathrm{Zn}$ matrix by a comparable amount $\left(\approx 122^{\circ}\right)$. Rasmussen and Loper Jr. (1975) observed a maximum undercooling of $160^{\circ}$ for $\mathrm{Bi}$ emulsions prepared by both air and ditertiary butyl peroxidation. The unspecified surface layer formed during emulsification in the experiments of Perepezko (1984) is supposed to be less catalytic than the solid $\mathrm{Zn}$ or Al surfaces of the present case and hence resulted in highest level of undercooling for $\mathrm{Bi}$ reported till date.

The $\Delta T$ values of $0.25 T_{\mathrm{m}}$ and $0.28 T_{\mathrm{m}}$ for $\mathrm{Bi}$ in $\mathrm{Zn}$ and Al matrices, respectively reflect significant difference in the relative nucleation efficiencies of the two matrices. Similar result had also been observed for entrapped Sn droplets (Southin and Chadwick 1978).

The present findings, however, do not seem to fully support the conclusions of Sundquist and Mondolfo (1961), that metals with simple structures were poor heterogeneous nucleants and those with complex structures were good heterogeneous nucleants. The lattice misfit theory (Cibula 1949-1950; Reynolds and Tottle 1951; Turnbull and Vonnegut 1952), which states that nucleated solid and the nucleating catalyst should have similar crystal structures for good heterogeneous nucleation, i.e. for low undercooling, rather seems to be in little agreement with the present experimental results. As observed by Southin and Chadwick (1978), an increasing trend in the degree of undercooling for $\mathrm{Bi}$ with increase in melting point of the substrate is found in the present investigation.

On the basis of the observation of Takahashi and Tiller (1969) and Acrivos (1976), which gives linear relationship between liquid drop size and undercooling (increase in $\Delta T$ for smaller diameter particles and vice versa), it accordingly appears that only small droplets produced either through rapid quenching or monotectic reaction have undergone deep levels of undercooling. This in turn implies a greater chance only of smaller droplets to be impurity free.

The theory of Tiller and Takahashi (1969) predicts an electrostatic contribution to the total interfacial energy at the catalyst/nucleus interface in controlling heterogeneous nucleation behaviour. According to this theory if the 
differences in electron work function $(\Delta \psi)$ between the substrate and nucleus were positive, the analysis indicated the substrate material to be a good nucleant whereas for negative $\Delta \psi$ it suggested a rather poor nucleating effect of the substrate. Based on the available data of electron work function (Weast 1977), $\Delta \psi$ is 0.06 and 0.11 , both positive, for $\mathrm{Al}-\mathrm{Bi}$ and $\mathrm{Zn}-\mathrm{Bi}$ systems, respectively. In view of the above, this model is not in agreement with the present findings. This rather suggests further examination of the theory of Tiller and Takahashi (1969).

At the highest level of undercooling, which is restricted to fine droplets only, it is assumed that a single nucleation event is sufficient for the solidification of each fine droplet. The nucleation rate thus calculated from the DSC thermogram recorded at $2.5 \mathrm{~K} / \mathrm{min}$, on the basis of the expression used by Rasmussen and Loper Jr. (1976) and Boswell and Chadwick (1980) corresponds to some average temperature of the sample during the time interval, $\Delta t$ (very small). Because of the slow cooling rate $(2.5 \mathrm{~K} / \mathrm{min})$, sample temperature does not change appreciably over the time interval, $\Delta t$.

In the approximation of a spherical nucleus the temperature dependence of nucleation rate for constant cooling experiment is given by the expression (Turnbull 1952)

$$
J=A \exp \left(-\frac{\Delta G^{*}}{k T}\right),
$$

where $\Delta G^{*}$ is the thermodynamic barrier to nucleation and $A$ a factor which is practically insensitive to small changes of temperature. For heterogeneous nucleation process, $A$ is of the order of $10^{25 \pm 1} \mathrm{~s}^{-1} \mathrm{~cm}^{-2}$ (Turnbull 1950a).

For heterogeneous nucleation process

$$
\Delta G^{*}=\frac{16 \pi \sigma^{3}}{3 \Delta G_{\mathrm{V}}^{2}} f(\theta),
$$

where $f(\theta)=1 / 4\left(2-3 \cos \theta+\cos ^{3} \theta\right), \theta$ being the contact angle. $\sigma$ and $\Delta G_{\mathrm{V}}$ in (2) are solid-liquid interfacial tension and volume free energy change during crystallization, respectively. For determining temperature dependence of nucleation rate for $\mathrm{Bi}$ in $\mathrm{Al}$, like $\mathrm{Bi}$ in $\mathrm{Zn}$ (Chaubey et al 1987), expression for the Gibbs free energy change $\left(\Delta G_{\mathrm{V}}\right)$ accompanying crystallization of an undercooled melt due to Lele et al (1985) has been used suitability of which has already been checked by Chaubey et al (1987). Combining (1) and (2) and using the expression of Lele et al (1985) for $\Delta G_{\mathrm{V}}$, expression for the heterogeneous nucleation process is written as

$$
J=A \exp \left[-\frac{16 \pi \sigma^{3} f(\theta)}{3 k \Delta S_{\mathrm{f}}^{2} C}\right],
$$

where

$$
C=T \Delta T^{2}\left(1-\frac{\Delta C_{\mathrm{Pf}}}{\Delta S_{\mathrm{f}}} \frac{\Delta T}{\left(T_{\mathrm{f}}+T\right)}\right)^{2} .
$$

$\Delta S_{\mathrm{f}}$ and $\Delta C_{\mathrm{Pf}}$ are entropy and heat capacity differences between liquid and solid at the melting point and are easily accessible quantities. Equation (3) gives a linear relationship between $\ln J$ and $C^{-1}$ as shown in figure 5 , which finally gave the value of $\Delta G^{*}$ as $47.085 \mathrm{kcal} / \mathrm{mole}$. Further, the gradient, $m=16 \pi \sigma^{3} f(\theta) / 3 k \Delta S_{\mathrm{f}}^{2}$, of (3) enables to calculate $\sigma^{3} f(\theta)$, which in turn helps calculating the wettability factor, $f(\theta)$, provided reliable value of interfacial tension between the crystal and liquid, $\sigma$, is known. Published values of $\sigma$ for metals are generally scanty because most of them have been estimated from Turnbull's classical homogeneous nucleation experiments on pure metals. With consistent refinements in the techniques, the undercooling limits have been continuously increasing, so uncertainty in the values is quite likely. Previously determined values of $\sigma$ for $\mathrm{Bi}$, based on undercooling measurements are $54.4 \mathrm{ergs} / \mathrm{cm}^{2}$ (Turnbull 1950a) and $79.3 \mathrm{ergs} / \mathrm{cm}^{2}$ (Perepezko et al 1979). Glicksman and Vold (1971) obtained a value of $82 \pm 4 \mathrm{ergs} / \mathrm{cm}^{2}$ at the melting point of $\mathrm{Bi}$. Mondolfo et al (1984-85) have reported a value of $83 \mathrm{ergs} / \mathrm{cm}^{2}$ at the melting point. A comparative study shows that the value of $\sigma$ changes very little between nucleation temperature and equilibrium melting temperature and hence in the present communication its temperature dependence has been neglected. Substitution of the values of $\sigma$ (Mondolfo et al 1984-85), $k$ (Boltzmann's constant) and $\Delta S_{\mathrm{f}}$ (for $\mathrm{Bi}$ ) in the gradient value, obtained from the plot of figure 5 , gave a value of 0.817 for the wettability factor, $f(\theta)$. This finally gives the value of contact angle, $\theta$, as $117^{\circ}$, which nucleating $\mathrm{Bi}$ makes with the $\mathrm{Al}$ substrate, at the highest undercooling observed. Earlier calculations by Chaubey et al (1987) have given $f(\theta)=0.486$ and $\theta=89^{\circ}$ for nucleating $\mathrm{Bi}$ on $\mathrm{Zn}$ substrate at the observed maximum undercooling. This simply indicates that $\mathrm{Bi}$ wets $\mathrm{Zn}$ more as compared to $\mathrm{Al}$ and that is the reason why higher $\Delta T$ for $\mathrm{Bi}$ is obtained in $\mathrm{Al}$ matrix rather than in the $\mathrm{Zn}$ matrix. $\Delta G^{*}$ values for $\mathrm{Bi}$, which are $47.085 \mathrm{kcal} / \mathrm{mole}$ and $39.8 \mathrm{kcal} /$ mole (Chaubey et al 1987) in $\mathrm{Al}$ and $\mathrm{Zn}$ matrices, respectively further confirm the above statement and conclude that $\mathrm{Zn}$ provides more efficient catalyst surface as compared to $\mathrm{Al}$.

\section{Conclusions}

The present study reveals that undercooling achieved is strongly dependent on the catalytic activity of the surface of the matrix entrapping second phase particles. Reduction in size of the droplets, achieved through whatsoever means, is not the only requirement for increasing the undercooling limits.

\section{Acknowledgements}

The author is grateful to Prof. P Ramachandra Rao and Prof. S Lele for helpful discussions during the course of this work. 


\section{References}

Acrivos C 1976 J. Mater. Sci. 111752

Andersen H H and Johnson E 1995 Nucl. Instrum. Meth. Phys. Rev. B106 480

Aoyama T, Paradis P F, Ishikawa T and Yoda S 2004 Mater. Sci. Eng. A375-377 460

Boswell P G and Chadwick G A 1980 Acta Metall. 28209

Chattopadhyay K 1992 Bull. Mater. Sci. 15515

Chattopadhyay K and Ramachandrarao P 1980 J. Mater. Sci. 15 685

Chaubey S, Singh V and Ramachandrarao P 1987 Bull. Mater. Sci. 9277

Chaubey S, Singh V and Ramachandrarao P 1988 Trans. IIM 41 147

Cibula A 1949-50 J. Inst. Metals 76321

Coombes C J 1972 J. Phys. F2 441

Devaud G and Turnbull D 1987 Acta Metall. 35765

Dobatkin V I, Elagin V I, Mudrenko G A and Sizova R M 1979 Russ. Met. 188

Duwez P, Willens R H and Klement W 1960 J. Appl. Phys. 31 1136

Fecht H J and Johnson W L 2004 Mater. Sci. Eng. A375-377 2

Fehling J and Scheil E 1962 Z. Metallkde. 53593

Fisher J C 1948 J. Appl. Phys. 191062

Glicksman M E and Vold C L 1971 Scr. Metall. 5493

Goswami R and Chattopadhyay K 1996 Appl. Phys. Lett. 69 910

Goswami R and Chattopadhyay K 1999 Philos. Mag. Lett. 79 481

Graves A and Perepezko J H 1986 J. Mater. Sci. 214215

Klement W, Jayaraman A and Kennedy G C 1963 Phys. Rev. 131632

Lacy L L, Robinson M B and Rathz T J 1981 J. Cryst. Growth 5147

Lele S, Dubey K S and Ramachandrarao P 1985 Curr. Sci. 54994

Mondolfo L F, Parisi N L and Kardys G J 1984-85 Mater. Sci. Eng. 68249
Mueller B A, Richmond J J and Perepezko J H 1985 Rapidly quenched metals: Proc. fifth. int. conf. (eds) S Steeb and $\mathrm{H}$ Warlimont (Wurzberg University, West Germany: Elsevier) Vol. I, p. 47

Ojha S N 2001 Mater. Sci. Eng. A304-306 114

Perepezko J H 1980 Rapid solidification processings: Principles and technologies in Proc. second int. conf. (eds) $\mathrm{R}$ Mehrabian et al (Virginia: Claitor's Publishing Division) p. 56

Perepezko J H 1984 Mater. Sci. Eng. 65125

Perepezko J H, Rasmussen D H, Anderson I E and Loper Jr C R 1979 Solidification and casting of metals (London: Metals Society) p. 169

Rasmussen D H and Loper Jr C R 1975 Acta Metall. 231215

Rasmussen D H and Loper Jr C R 1976 Acta Metall. 24117

Reynolds J A and Tottle C R 1951 J. Inst. Metals 8093

Shiraishi S Y and Wood R G 1964 Can. Met. Quar. 3117

Singh A and Tsai A P 2003 Sadhana 2863

Southin R T and Chadwick G A 1978 Acta Metall. 26223

Sundquist B E and Mondolfo L F 1961 Trans. AIME 221157

Takagi M 1954 J. Phys. Soc. Jap. 9359

Takahashi T and Tiller W A 1969 Acta Metall. 17643

Thoft N B, Bohr J, Buras B, Johnson E, Johansen A, Andersen H H and Sarholt-Kristensen L 1995 J. Phys. D: Appl. Phys. 28539

Tiller W A and Takahashi T 1969 Acta Metall. 17483

Turnbull D 1950a J. Appl. Phys. 211022

Turnbull D 1950b J. Metals 1881144

Turnbull D 1952 J. Chem. Phys. 20411

Turnbull D 1969 Comtemp. Phys. 10473

Turnbull D and Cech R E 1950 J. Appl. Phys. 21804

Turnbull D and Vonnegut B 1952 Ind. \& Eng. Chem. 441292

Volmer M 1929 Z. Electrochem. 35555

Vonnegut B 1948 J. Colloid. Sci. 3563

Wang C C and Smith C S 1950 Trans. AIME 188136

Weast R C 1977 CRC handbook of chemistry and physics (Cleveland: CRC Press) 58th ed. 